\title{
A Comprehensive Research of Atmospheric Haze by Optical Remote Sensing in Central China Region (CCR)
}

\author{
Wenqing Liu, Zhenyi Chen, Pinhua Xie, \\ Jianguo Liu and Tianshu Zhang \\ Additional information is available at the end of the chapter \\ http://dx.doi.org/10.5772/59753
}

\section{Introduction}

With the changing pollution scenario, the task of improving air quality is now faced with increasingly serious challenges. Aerosols and gaseous pollutants have great impact on the radiative balance of the Earth, and thus on climatic changes. Furthermore, the radiative forcing of natural and anthropogenic aerosols exhibits a strong seasonal and geographical variability, which can affect the diffusion of atmospheric pollution locally [1]. The increase of aerosols or gaseous pollutants results in impairment of visibility. Besides, high aerosol concentration is deleterious to human health. The Chinese Academy on Environmental Planning considers that air pollution is responsible for 411,000 premature deaths in China in 2003, primarily from respiratory problems and heart diseases [2]. Therefore, obtaining information on the vertical distribution of aerosols and gaseous pollutants in the pollution haze is crucial to understanding their optical characteristics as well as their impact on air quality and on human health.

During the past 10 years, with its dense population, rapid economic growth, and dramatic rate of urbanization, China has been experiencing elevated levels of air pollution [3-5]. This is particularly so in the case of the Pearl River Delta (PRD), Yangtze River Delta (YRD), and Central China Region (CCR). Among these, the CCR region is where the frequency of occurrence of haze has been increasing rapidly from 2012. In CCR, NOx, $\mathrm{SO}_{2}$ and VOCs discharged by pollution sources are the significant primary pollutants, which greatly influence the formation of particulate matter and ozone because of photochemical reaction. Besides, the prevalence of mild and humid climate throughout the year in CCR leads to transformation and accumulation of particulate matter and gaseous pollutants. In 
addition, regional transportation contributes to combined pollution problems of atmosphere, manifested by high-concentration fine particulate matter, low visibility, highconcentration $\mathrm{NO}_{2}$ column, etc.

Thus far, extensive studies using different methods have been conducted in China on atmospheric pollution [6-9]. For a better understanding of aerosol properties and their effect on environment, two major aerosol experiments were conducted in mainland China since 2004: (i) East Asian Study of Tropospheric Aerosols -An International Regional Experiment (EASTAIRE) [10] and (ii) East Asian Study of Tropospheric Aerosols and Impact on Regional Climate (EAST-AIRC) [11]. Information on the properties of aerosols and their temporal and spatial distribution was obtained from studies using both short-term intensive field experiments and long-term operations, as well as modeling studies. Besides these filed experiments, lidar (LIght Ranging and Detection) and DOAS (Differential Absorption Spectroscopy) studies were conducted at several sites in China[12-18]. However, knowledge on the properties of aerosols and trace gases, particularly in the vertical dimension, in CCR China is rather scanty. Also, because of lack of real-time data on the quantum of pollutants discharged by major industrial parks, it is hard to resolve the task of pollution prevention. The present research was designed to take advantage of advanced environmental monitoring technical equipment (including Lidar[19,20], multi-axis DOAS[21,22], vehicle-mounted DOAS /infrared SOF[23-25], and meteorological parameter analyzer, etc.) to establish a stereoscopic observing system for key sources of regional pollution in CCR, China. The campaign was carried out from Dec 2013 to April 2014 in three key cities, namely Anyang (AY), Jiaozuo (JZ) and Sanmenxia (SMX). Continuous and automatic stereoscopic monitoring of primary pollution sources, transportation of pollutants, emission characteristics of pollution from major industrial parks, as well as the transport conditions in the surrounding regions of pollution under specific meteorological conditions was carried out to obtain data that can help in air quality improvement and in development of forecast warning model, besides making up for the deficiency in current ground monitoring system.

The scope of research resolves mainly into two parts:

1. Real-time monitoring of spatio-temporal distribution of regional haze pollution:

Representative monitoring points were identified in selected cities and surrounding areas along the direction of pollution transportation to measure spatial and temporal distribution characteristics of $\mathrm{SO}_{2}, \mathrm{NO}_{2}$ and aerosol particulate matter with lidar, MAX-DOAS, etc.

2. Real-time monitoring of disorganized pollutant discharge in key industrial park sources:

VOC is an important precursor to the formation of photochemical smog. The type and volume of VOC discharge, as also of $\mathrm{SO}_{2}$ and $\mathrm{NO}_{2}$, play a significant role in pollution. Aiming at the key source areas of elevated discharge, vehicle-mounted DOAS and vehicle-mounted SOFFTIR were utilized for mobile scanning measurement of discharged smoke plumes. Using the absorption characteristics of pollution gas molecules in infrared and ultraviolet spectrum, the concentration of exhaust gas was qualitatively and quantitatively determined through SOFFTIR and DOAS spectrum analytical methods. 


\section{Instrument and system}

\subsection{Lidar}

The Lidar system, used for the study of spatial and temporal distribution of atmospheric particles, is shown in Fig 1; it adopts 532m Mie scattering and 532 polarization channels. Laser transmitter launches linear polarization lasers at $532 \mathrm{~nm}$ by shooting vertically into atmosphere through beam expander, inversed mirror and quartz skylight. The laser pulse is scattered through air molecules, atmospheric aerosols or cloud, on its transmission route. The backwardscattered light firstly passes through skylight glass and then as parallel light through the diaphragm hole and convergent lens of the telescope. The converged parallel light is split into two beams by dichroic mirror: one is at $532 \mathrm{~nm}$, received by photomultiplier $C$ after passing through optical filter; the other is at $355 \mathrm{~nm}$, whose vertical and parallel components are received respectively by $\mathrm{A}$ and $\mathrm{B}$ photomultipliers, after decomposition by an analyzer prism. After the conversion of optical signal into electrical signal by photomultiplier, the signal will be delivered to data acquisition system, where its ASCII code data file will be recorded and saved by main control computer.

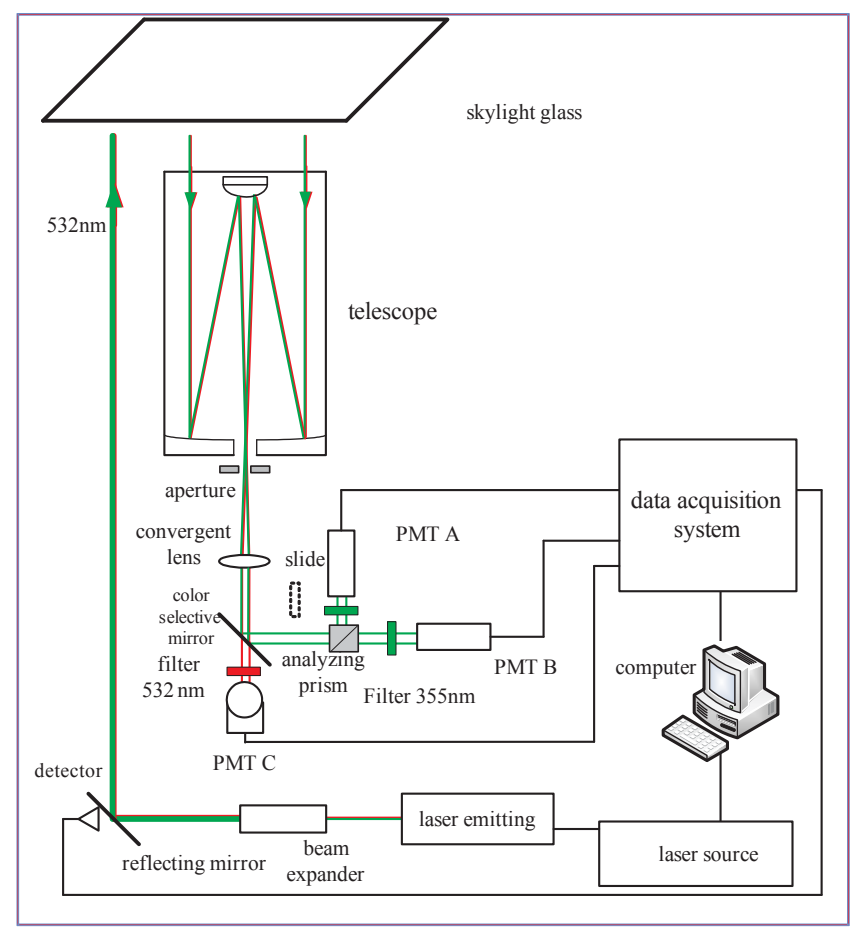

Figure 1. System structure of lidar 


\subsection{MAX-DOAS}

MAX-DOAS is a special type of DOAS technology, which uses characteristic absorption structure of trace gases (such as $\mathrm{NO}_{2}, \mathrm{SO}_{2}, \mathrm{O}_{3}$ ) in visible ultraviolet band for qualitative and quantitative analysis of gas. As a real-time and online measuring method, it is eminently suitable for remote sensing measurement of air pollution. Besides, the data on vertical column density of pollution gases acquired from this method can help in verifying satellite results [26]. MAX-DOAS receives scattered sunlight from telescopes at different elevations, as shown in Fig 2. Based on the characteristic absorption spectrums of pollution gas, it inverses the vertical column density of pollution gas and distribution profile of density. Besides, it acquires data on spatial distribution of pollution gas in atmosphere by measuring atmospheric absorption spectrums in zenith direction and several off-axis directions. During the monitoring process, the reflector orients itself to the north and is then driven by stepper motor to turn to $1^{\circ}, 2^{\circ}, 3^{\circ}$, $4^{\circ} . . .90^{\circ}$ to finish one measurement cycle, thus realizing measurement of different angles. The schematic diagram of MAX-DOAS is presented below.

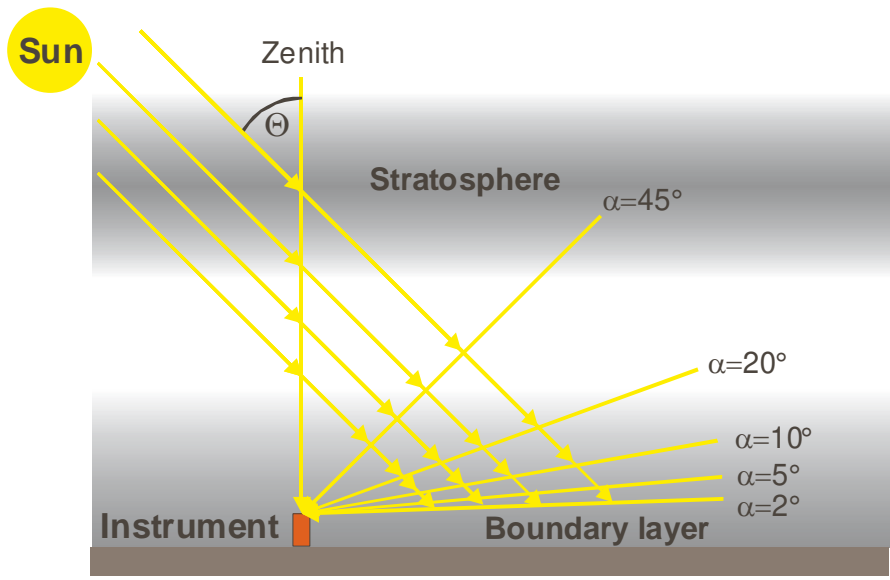

Figure 2. Schematic diagram of MAX-DOAS

\subsection{Vehicle-mounted DOAS}

With zenith-sky scattered light as the light source, vehicle-mounted DOAS technology is a kind of spectrum detection technology, which uses "fingerprint" absorption characteristics of optical radiation by gas molecule for qualitative and quantitative measurements of gas. The system includes mainly a spectrograph, a GPS system and a telescope [27]. As shown in Fig 3 , the whole system is put on mobile platform and the telescope gathers solar spectrum along the measurement route. During operation, the band of spectrograph is fixed at $290 \mathrm{~nm} \sim 420 \mathrm{~nm}$ (spectral region 130nm) as this band has strong $\mathrm{SO}_{2}$ and $\mathrm{NO}_{2}$ absorption structures. After the spectrograph delivers the gathered spectrum to computer for data processing, DOAS method is used to calculate the column density of pollution gas. Finally, density distribution of 
pollution gas on the measuring route can be acquired by combing the information from GPS on longitude and latitude.
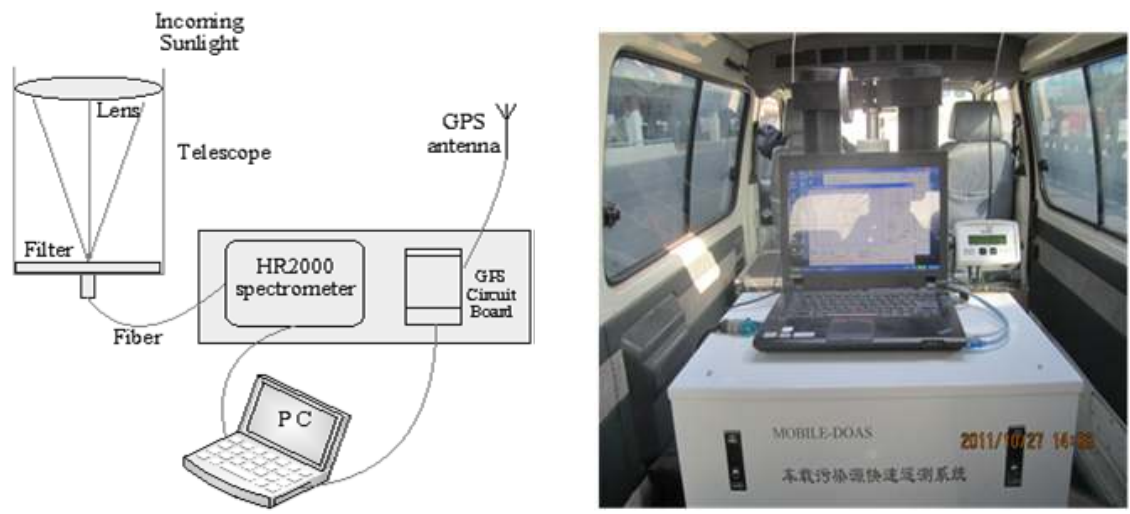

Figure 3. Structure and system of vehicle-mounted DOAS

\subsection{Satellite}

The spatial resolution of the OMI detector mounted on AURA satellite is $13 \mathrm{~km} \times 24 \mathrm{~km}$ [28]. $\mathrm{NO}_{2}$ VCD of troposphere, below the satellite orbit, can be obtained through DOAS inversion of measured spectrum. After differential and meshing treatment, $\mathrm{NO}_{2} \mathrm{VCD}$ of each acquired orbit is integrated and then $\mathrm{NO}_{2}$ density distribution over the region is obtained. Acquisition of regional density distribution data is significant for investigation of the processes of generation and transportation of pollution. For the present study, OMI Level $2 \mathrm{NO}_{2}$ VCD data was adopted. From the weekly average between Nov and Dec, it was found that CCR pollution reached its peak in the third week.

\section{Results and discussion}

\subsection{Stereoscopic monitoring of regular pollution gas}

1. Comparison of areal distribution at the three sites

The average of the values obtained during measurement period at the three observation sites (AY, JZ and SMX) were taken as the areal distribution level of $\mathrm{NO}_{2}$ and $\mathrm{SO}_{2}$ in CCR (Fig 4). It can be observed that the average level of $\mathrm{NO}_{2}$ density at $\mathrm{AY}$ is $63.4^{*} 10^{15} \mathrm{molec} . \mathrm{cm}^{2}$, which is higher than the values at JZ and SMX. Density of $\mathrm{NO}_{2}$ in SMX is the lowest at its average level of $35.3^{*} 10^{15}$ molec. $/ \mathrm{cm}^{2} . \mathrm{SO}_{2}$, density at JZ is the highest at $149^{*} 10^{15} \mathrm{molec} . / \mathrm{cm}^{2}$, which is higher than that at AY and SMX. 

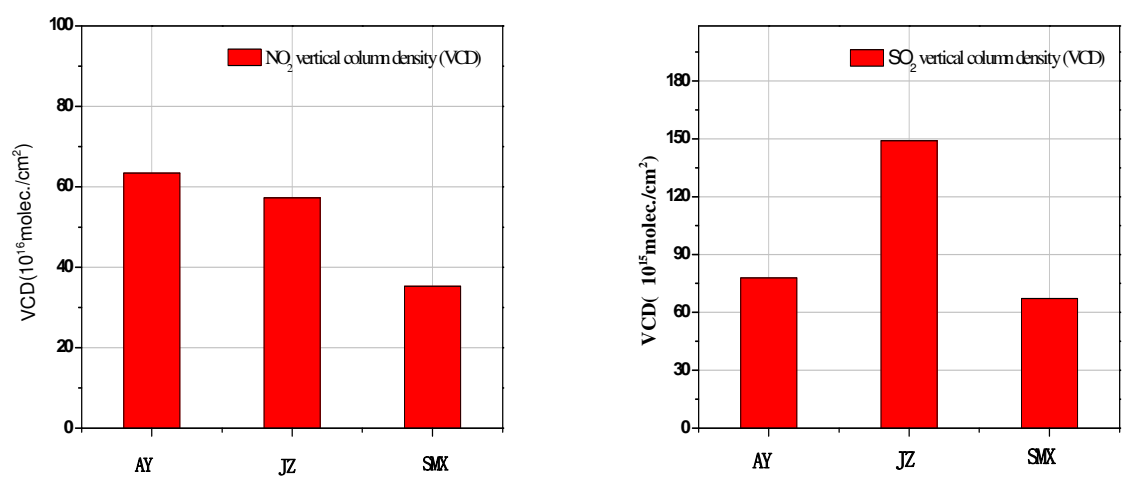

Figure 4. Characteristic contrasts about VCD (vertical column density) of $\mathrm{SO}_{2}$ and $\mathrm{NO}_{2}$ at the three sites

2. Results of monthly average variation

The results obtained during the measurement period were used to calculate the averages of different months and to analyze variation trends of pollutant concentration. It can be observed from the calculation results (see Fig 5) that $\mathrm{NO}_{2} \mathrm{VCD}$ (vertical column density) reached its peak in Dec and Jan, decreased from Feb onward, and then remained low between Mar and June. Monthly average of $\mathrm{SO}_{2} \mathrm{VCD}$ at each station is shown in the figure below. It is obvious from $\mathrm{VCD}$ of $\mathrm{SO}_{2}$ is high in winter just as $\mathrm{NO}_{2}$; it reached its peak in Dec at AY, in Jan at SMX, and in Feb at JZ. It obviously decreased from Mar and thereafter remained low up to June.
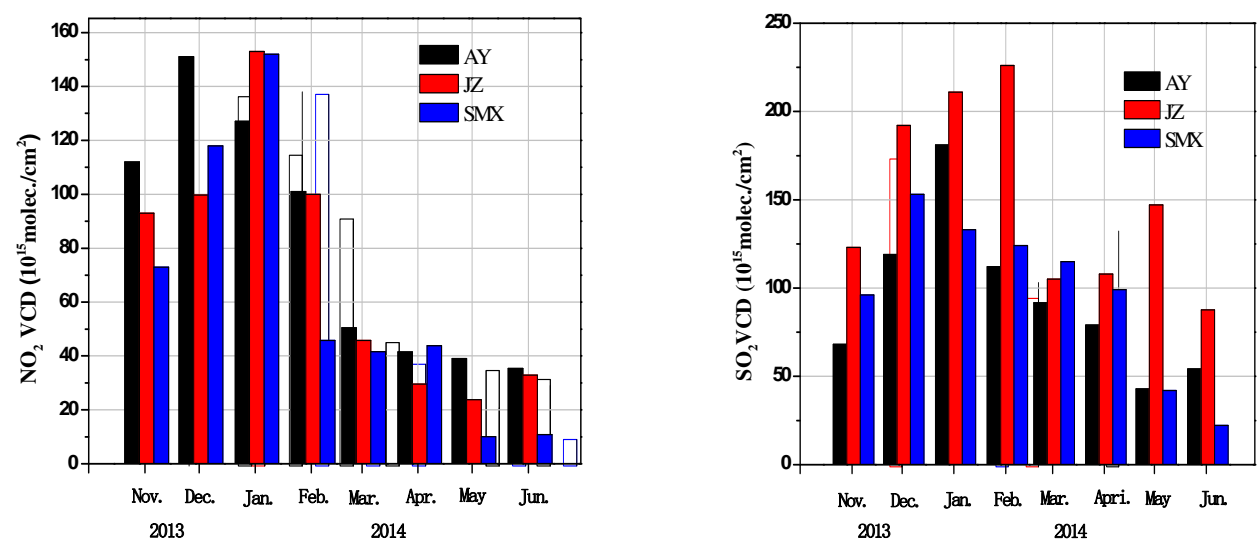

Figure 5. Monthly average variations about $\mathrm{VCD}$ (vertical column density) of $\mathrm{SO}_{2}$ and $\mathrm{NO}_{2}$ in observing sites

From an overview of the monthly averages discussed above, it can be concluded that the accumulation of pollutants had been accumulated rapidly and heavily because of high discharge and unfavorable weather conditions in winter. With the end of hot season after 
February, change of wind direction and increase in rainfall would start favoring diffusion and sedimentation of pollutants, and consequently reduction of pollutant concentration.

\subsection{Stereoscopic monitoring of aerosols}

Monitoring of aerosols through lidar, from Nov 2013 to April 2014, (Fig 6) revealed that haze pollution was severe mainly from Nov. 2013 to Jan. 2014. Particularly from Dec 12 to Dec 20, and Jan 4 to Jan 17, the pollution lasted for almost half a month at AY and JZ. Overall air quality improved continuously, from Feb to June 2014, at AY, JZ and SMX. However, during wheat harvesting in June, because of straw burning, pollution levels increased at AY, JZ and SMX sites. The highest pollution levels were confined to the middle of June $\left(14^{\text {th }}-15^{\text {th }}\right)$; the peak of aerosol extinction coefficients at AY, JZ and SMX sites are respectively $0.83 \mathrm{~km}^{-1}, 0.91 \mathrm{~km}^{-1}$ and $0.66 \mathrm{~km}^{-1}$.

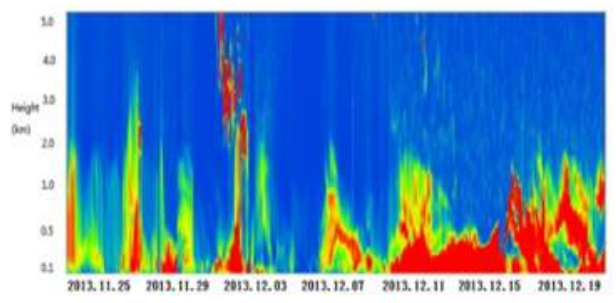

Nov 25, 2013-Dec 25, 2014

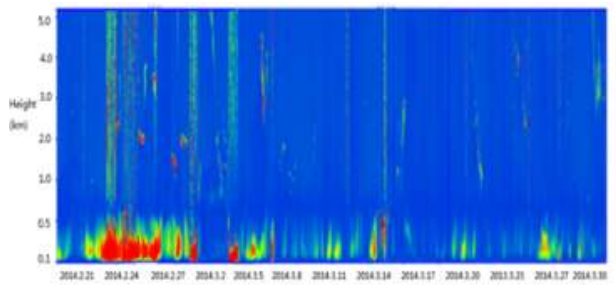

Feb 20, 2014-Mar 30, 2014

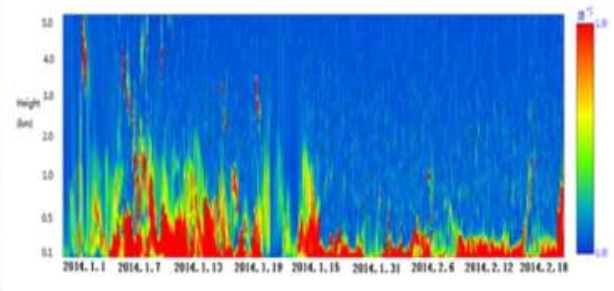

Jan 1, 2014-Feb 28, 2014

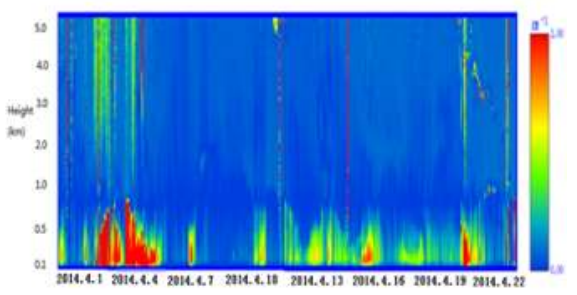

Apr 1, 2014-Apr 22, 2014

Figure 6. Monthly aerosol distributions from lidar observation

Pollution transportation (Nov 25, 2013-Nov 27, 2013) also occurred at AY, JZ and SMX, but the pollution characteristics and sources were different. Among these three sites, sand dust transportation in northwest direction affected SMX the most. Because of sand dust transportation, large particle concentration in air increased and $\mathrm{RH}$ decreased rapidly (at SMX, $\mathrm{RH}=78 \%$ on Dec 25 and $\mathrm{RH}=32 \%$ on Dec 27). Repeated monitoring of local pollutions (Dec 12, 2013-Dec 17, 2013; Jan 8, 2014-Jan 11, 2014; Jan 27, 2014-Jan 31, 2014; Feb 16, 2014-Feb 18, 2014; Apr 10, 2014-Apr 13, 2014) reveal that near-ground pollution at these three sites came mainly from local pollution (industrial emission, motor vehicle exhaust and coal combustion) and fire coal transportation from southern cities in the southeast 
direction. By the end of Jan 2014, local pollution aggravated because of discharge from firecrackers during spring festival. The pollution at higher levels in the air above $1 \mathrm{~km}$ came mainly from the northwest.

In conclusion, it emerges that particulate pollution occurred almost simultaneously at the three sites AY, JZ and SMX. Local pollution (local source) is typical in AY, and near-ground pollution in JZ is higher due to the local industrial emission. Local pollution was relatively slighter in SMX, but it can be easily aggravated by northwest sand dust transportation. Sand dust pollution at AY manifests as superposed locally raised dust over northwest sand dust. In CCR, the ground weather conditions of uniform-pressure were conducive to pollutant diffusion. This weather had lower ground pressure field, lower ground and low-altitude wind speeds, and even calm wind sometimes. These were often accompanied by stronger radiation inversion or low-altitude temperature inversion that is difficult to eliminate. The structure of lower atmosphere layer was stable and might contribute to higher pollution.

\subsection{Vehicle-mounted monitoring of pollutant discharge in some representative cities and key industrial parks}

Quantitative modeling was done in some cities to evaluate the influence of key industries and industrial parks on ambient air quality, especially PM10. Vehicle-mounted DOAS system was used for monitoring industrial parks in both winter (Dec 2013) and summer (May-June, 2014) by way of acquiring data on spatial distribution of urban VOD of $\mathrm{SO}_{2}$ and $\mathrm{NO}_{2}$, emission characteristics of $\mathrm{SO}_{2}$ and $\mathrm{NO}_{2}$ in key industrial sources, as well as pollution transportation parameters under specific meteorological conditions.

At AY, the results obtained in winter and summer is similar. The concentration of $\mathrm{SO}_{2}$ and $\mathrm{NO}_{2}$ was caused mainly by the discharge from steelworks factories. However, observations during southeast/south winds in summer show that the concentration of $\mathrm{SO}_{2}$, in the southwestnorthwest section of the measurement route, was high. This indicates that sporadic small-scale industrial discharge occurred beyond southwest-northwest section (south and southwest of AY), which was not found during observations in winter. Judging from the relative geographic positions of steelworks and urban area at AY, as well as forward track model of wind field (Fig 7), it can be concluded that during northwest winds, discharge of AY steelworks had great influence on the air quality of urban area in AY.

Mean values per hour $(\mathrm{MV} / \mathrm{H})$, obtained from ground monitoring of $\mathrm{SO}_{2}$ at monitoring point of environmental protection agency in AY from May 18 to May 20 are shown in Fig 8. From these results, it can be observed that ground concentration of $\mathrm{SO}_{2}$ in urban area increased during northwest winds. At the same time, it is also found that during southeast winds, ground concentration of $\mathrm{SO}_{2}$ in urban area was high at about 11a.m. on May 18, when the observation time was just the same as that of third auxiliary chart in Figure 9. It is concluded that, under southeast wind field, sporadic pollution in the southwest and south, beyond measurement area, had great influence on the air quality of main urban area in AY. 


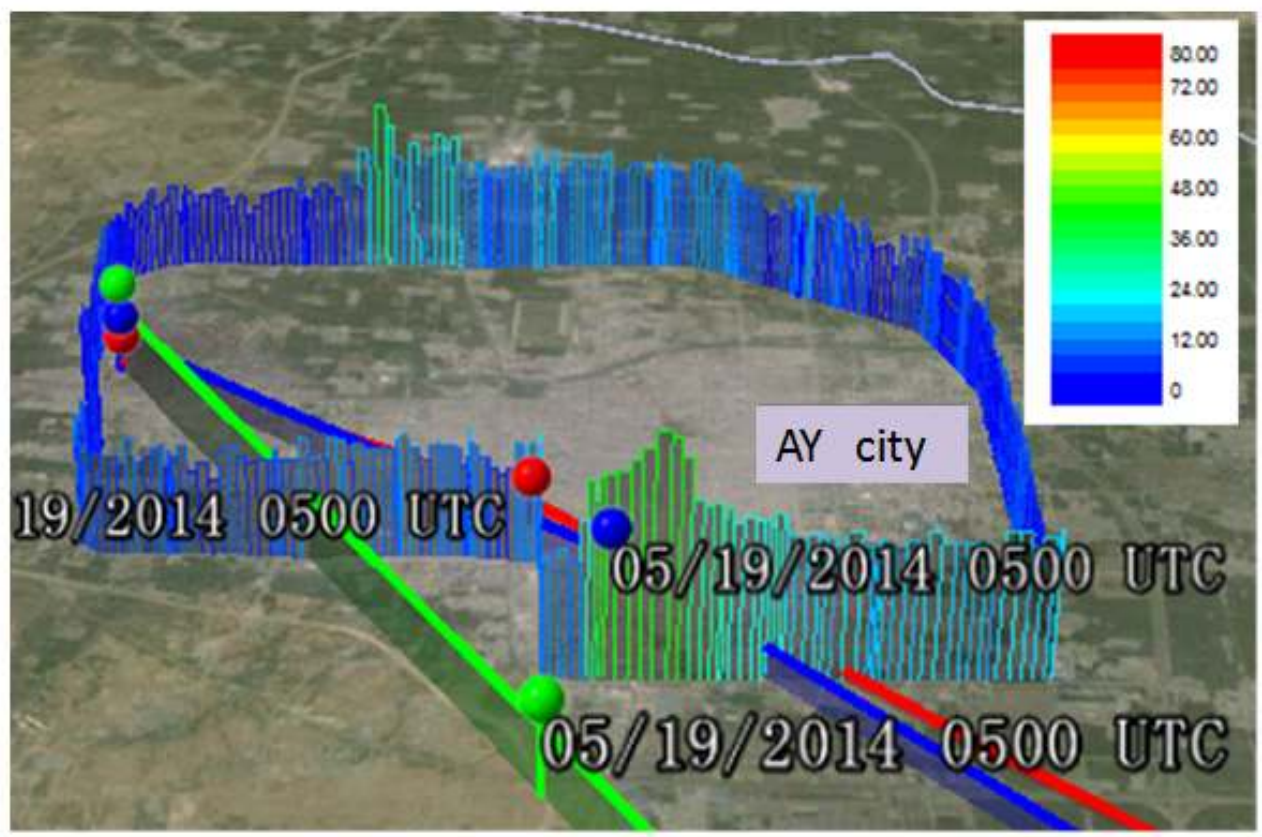

Figure 7. Spatial distribution of $\mathrm{SO}_{2}$ and wind field track superposition at $\mathrm{AY}$ under northwest wind field

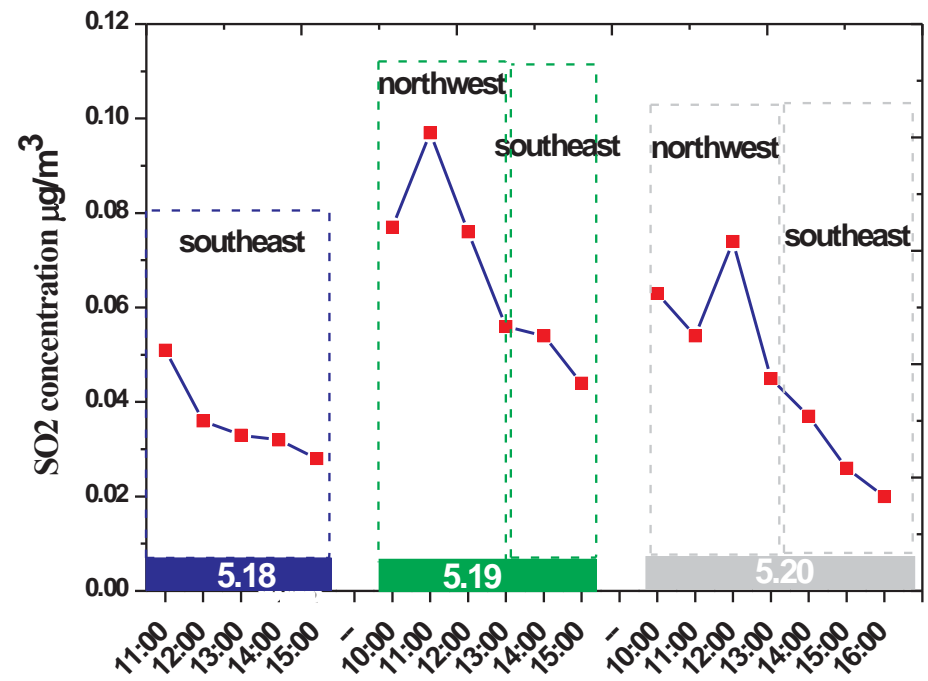

Figure 8. $\mathrm{MV} / \mathrm{H}$ about ground concentration of $\mathrm{SO}_{2}$ in monitoring point at $\mathrm{AY}$ 


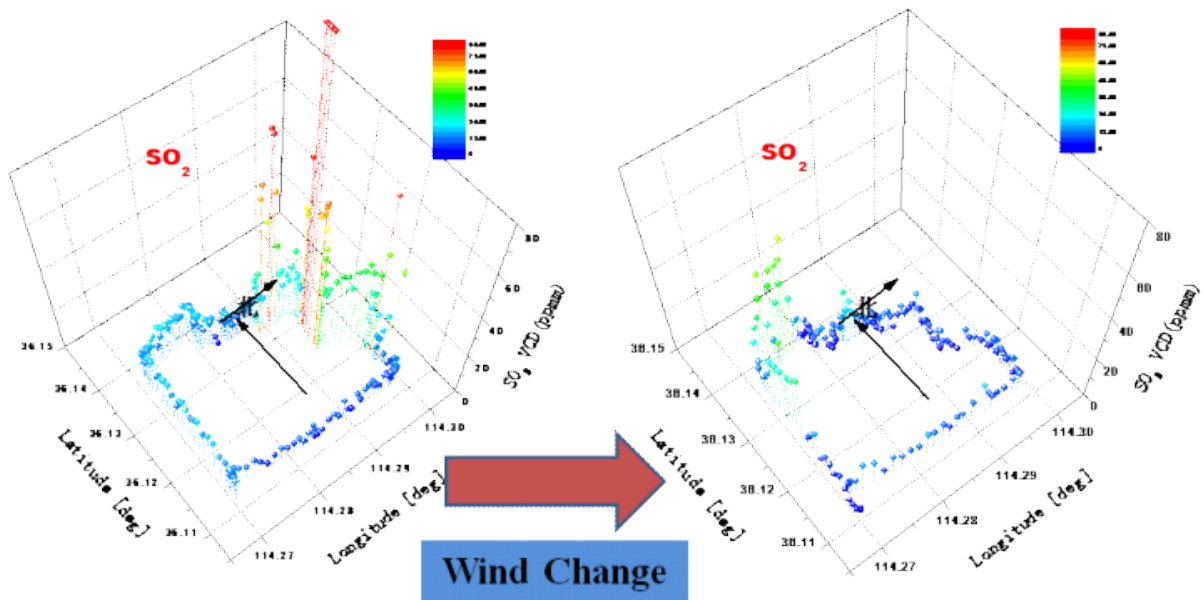

Figure 9. Spatial distribution changes of $\mathrm{SO}_{2}$ during the wind filed transformation process at $\mathrm{AY}$ steelworks

\subsection{Analysis of the typical haze process}

Haze episode (Dec 12, 2013-Dec, 16, 2013)

From Dec 12, 2013 to Dec 16, 2013, a typical haze phenomenon was observed at AY, JZ and SMX, when the pollution was mainly local. Under the influence of regional weak wind field, the distribution range of local pollution was large and the duration long, but intermittent. Besides, the extinction coefficient of aerosol and concentration of $\mathrm{NO}_{2}$ reflect a completely accumulative, rising, sustaining and stable process. Based on the distribution range and strength, two main phases were identified: generation phase of local pollution and pollution stabilization phase.

\section{Aerosols}

AY city: Since the afternoon of Dec 12, 2013, the pollutants gradually rose to $1.9 \mathrm{~km}$ and then began descending on Dec 13 (Fig 10). In the afternoon of Dec 14, it again started rising, but this time the height was lower than that on Dec 13. During Dec 15-16, near-ground pollution intensified and lasted for a long time, with the maximum value of extinction coefficient reaching $0.87 \mathrm{~km}-1$ (see Fig 11).

a. Formative period of haze (Dec 12-14)

b. Stable formation of pollution (Dec 15-16)

JZ city: The height of pollutants started rising from the afternoon of Dec 12 and the average of extinction coefficient was higher than that at AY (Fig 12). The height of daytime pollutants dropped on Dec 13, but it began rising again in the morning of Dec 14; near-ground pollution continued on Dec 15-16 (Fig 13). 

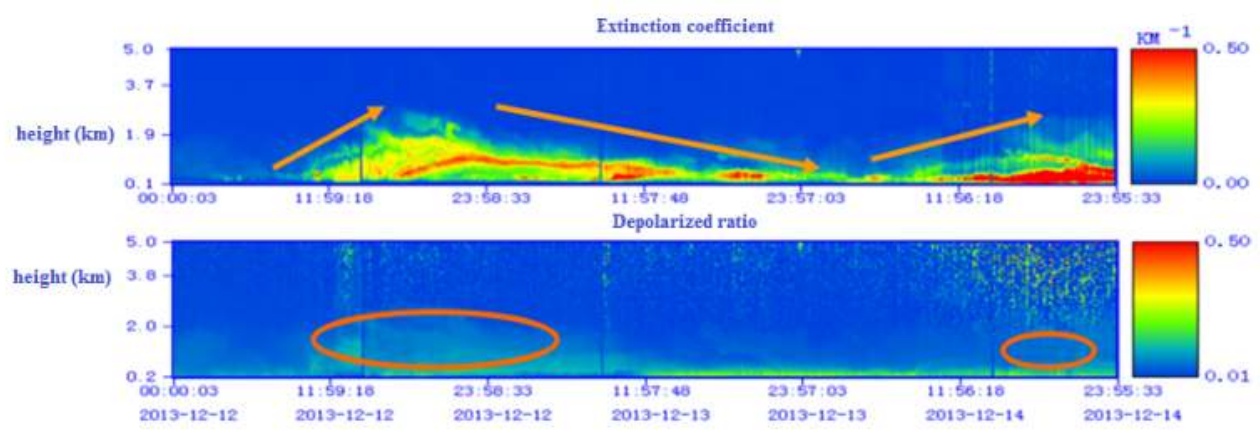

Figure 10. Spatial distributions of aerosols from Dec 12 to Dec 14 at AY, CCR

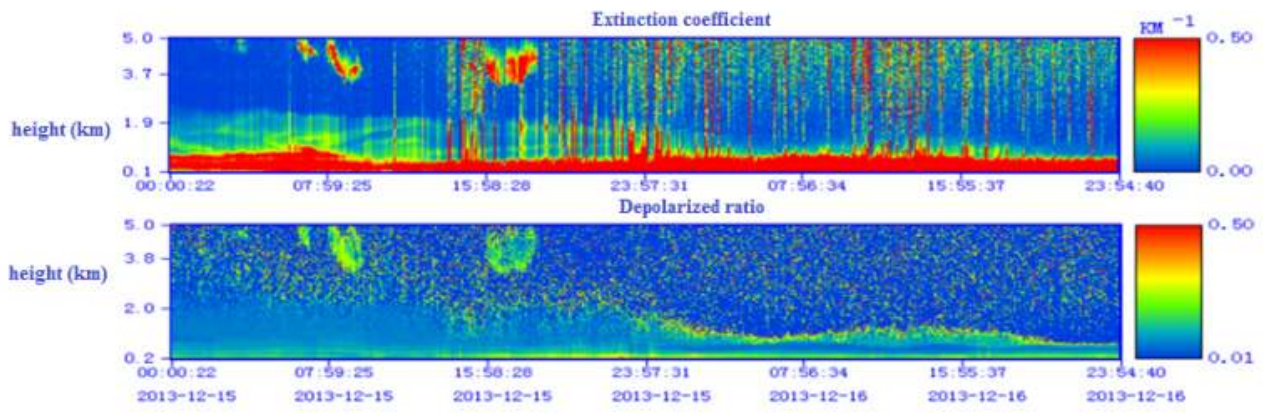

Figure 11. Spatial distributions of aerosols from Dec 15 to Dec 16 at AY, CCR

c. Formative period of haze (Dec 12-14)

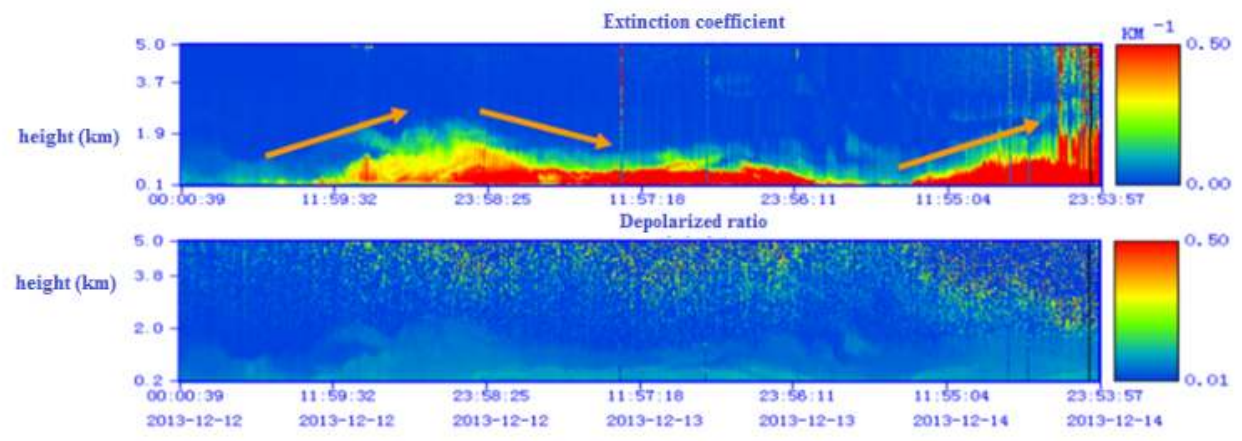

Figure 12. Spatial distributions of aerosols from Dec 12 to Dec14 at JZ, CCR 
d. Stable formation of pollution (Dec 15-16)

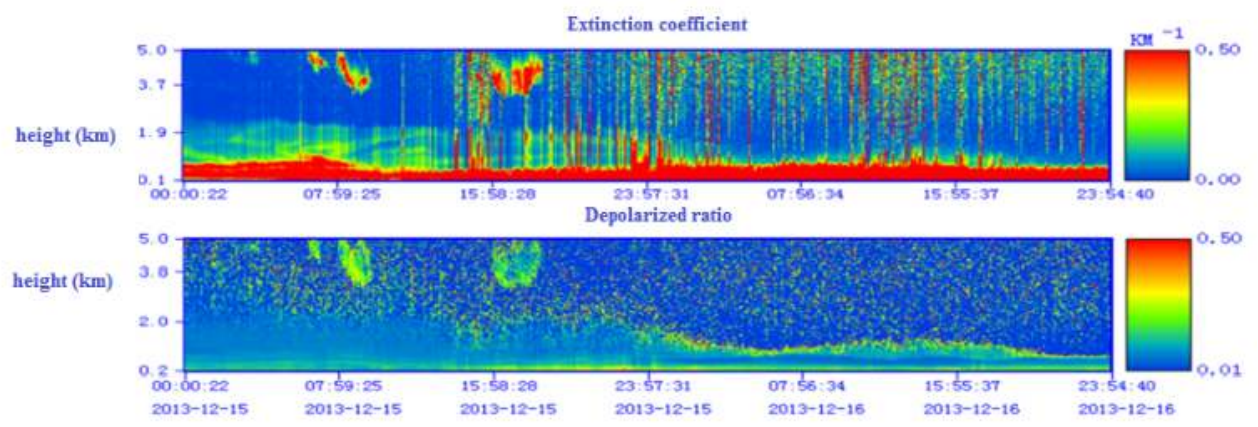

Figure 13. Spatial distributions of aerosols from Dec 15 to Dec16 at JZ, CCR

SMX city: Local pollution was noticed from the afternoon of Dec 12; the height of the pollutants rose gradually from the evening of Dec 13 and the average of extinction coefficient was $0.39 \mathrm{~km}^{-1}$ (Fig 14). High concentration pollution was confined to the period from the evening of Dec 13 to evening of Dec 14. No obvious change of extinction coefficient profile is observed on Dec 15-16; the height of the pollutants was below 1.2km (Fig 15).

e. Formative period of local pollution (Dec 12-14)

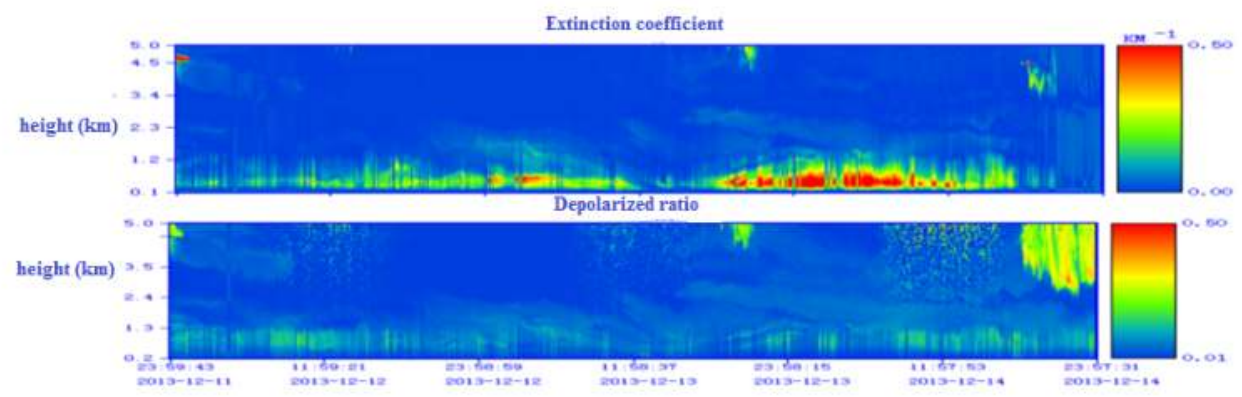

Figure 14. Spatial distributions of aerosols from Dec 12 to Dec 14 at SMX, CCR

f. Stable formation of pollution (Dec 15-16)

\section{Pollution gas}

During the haze period from Dec 14 to Dec 20, the whole process of $\mathrm{NO}_{2}$ accumulation and dispersion, as observed by MAX-DOAS, is depicted in Figs 16 \& 17. The changes in pollution concentration are most evident at AY, where the concentrate started rising since Dec 12 and 


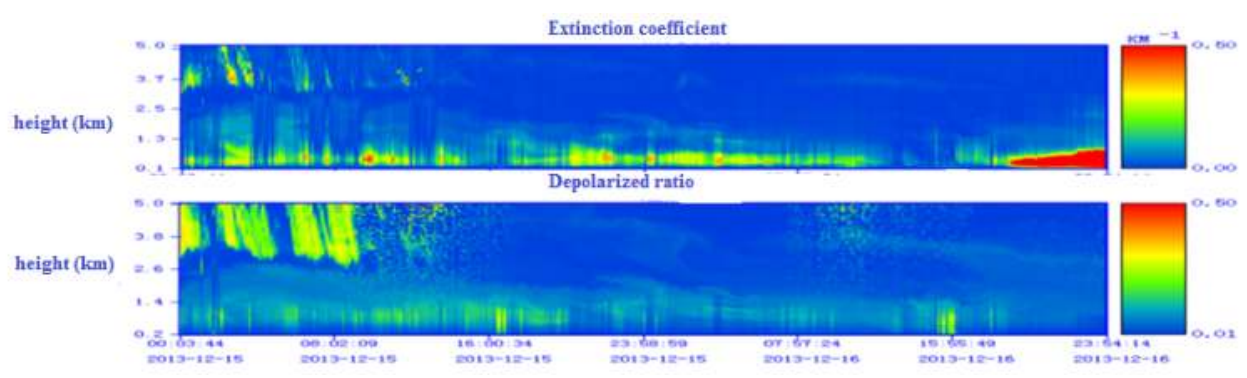

Figure 15. Spatial distributions of aerosols from Dec 15 to Dec16 at SMX, CCR

continued until Dec 14; thereafter, it remained at a high level. However, the increase at JZ was relatively slow. The concentration of both $\mathrm{NO}_{2}$ and $\mathrm{SMX} \mathrm{NO}$ increased obviously on Dec 14 and again, and this time is more higher on December 18. On the contrary, the concentrations of $\mathrm{NO}_{2}$ at $\mathrm{AY}$ and JZ began decreasing. The haze formation was caused mainly by internal and northern atmosphere transmission; besides, the obstruction to the airflow in the north militated against pollutant diffusion and instead favored accumulation. Air humidity, coupled with the convergence of cold and hot airflows, contributed to the process of haze formation.

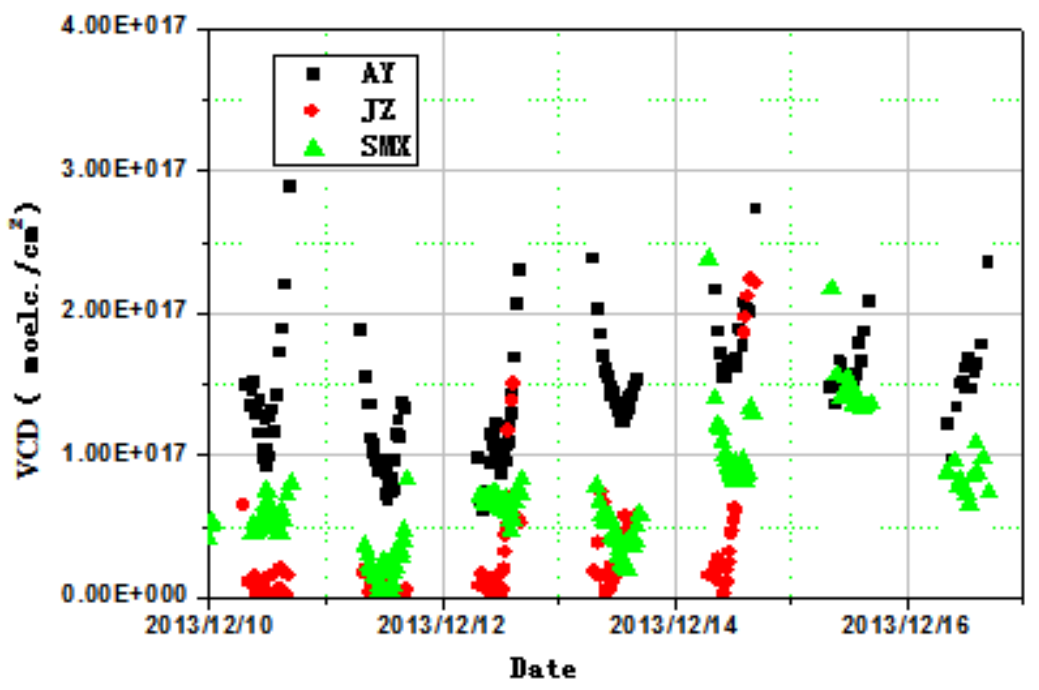

Figure 16. $\mathrm{NO}_{2} \mathrm{VCD}$ from Dec 10 to 16 in the observing sites

\section{Meteorological conditions}

On Dec 15 , the average wind speed was $4.1 \mathrm{~m} / \mathrm{s}$ and the temperature was $1.8^{\circ} \mathrm{C}$ at the height of $1000 \mathrm{~m}$. The prevailing wind was northwest wind (Fig 18). The high-altitude west wind was 

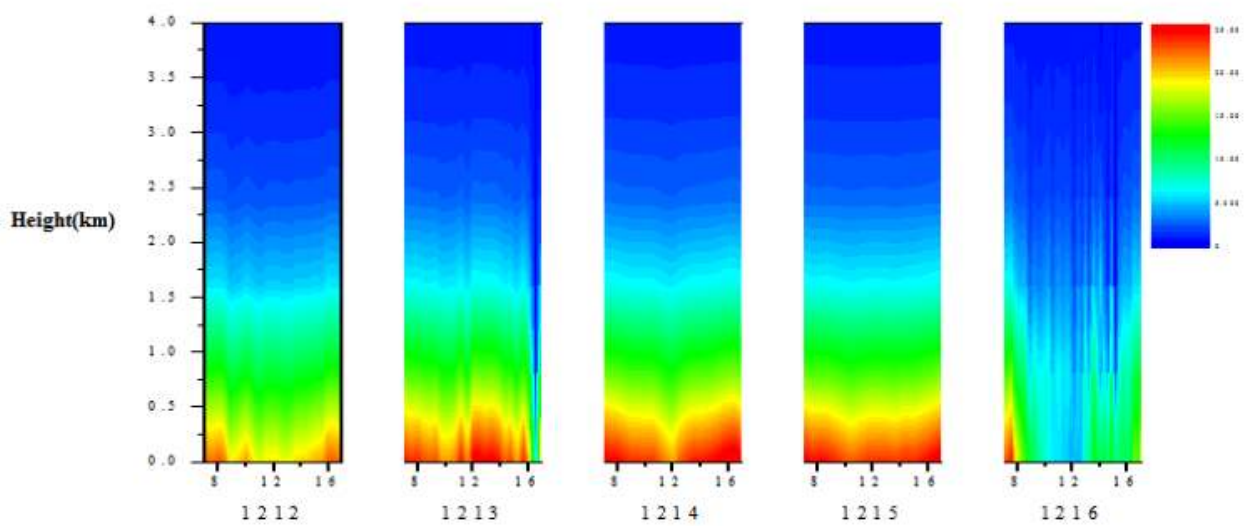

Figure 17. $\mathrm{NO}_{2}$ profiles from Dec 12 to 16 at $\mathrm{AY}, \mathrm{CCR}$

affected by the downdraft in leeward slope terrain, leading to the convergence of the regional weak wind field pollutants, and finally to heavy pollution.
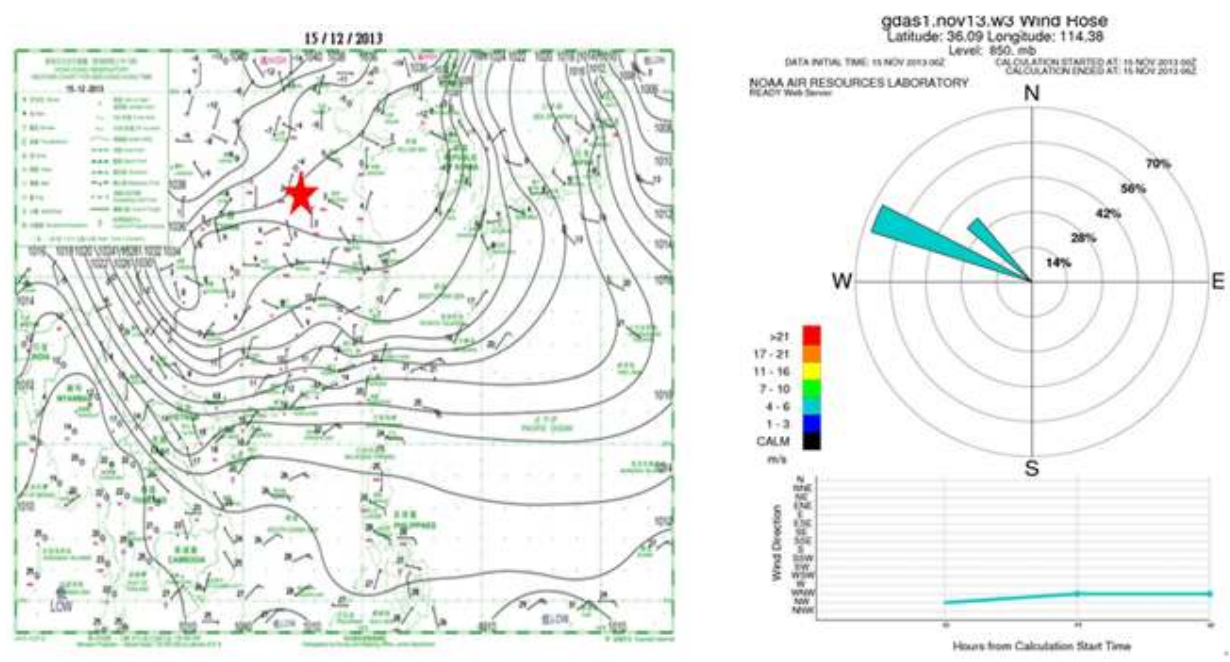

Figure 18. Meteorological conditions and wind rose diagram

From the HYSPLIT backward trajectory model in Fig 19 [29], the pollution at the three observation points was found to be mainly from the northwest. The main pollution source could be from burning of fossil fuels or bio-fuels, aided by the continental airstream. By noon on Nov 25, there was evident increase in pollutants at both AY and JZ. Subsequently, until the evening on Dec 26, at both the observation points, the pollutants decreased and then again 


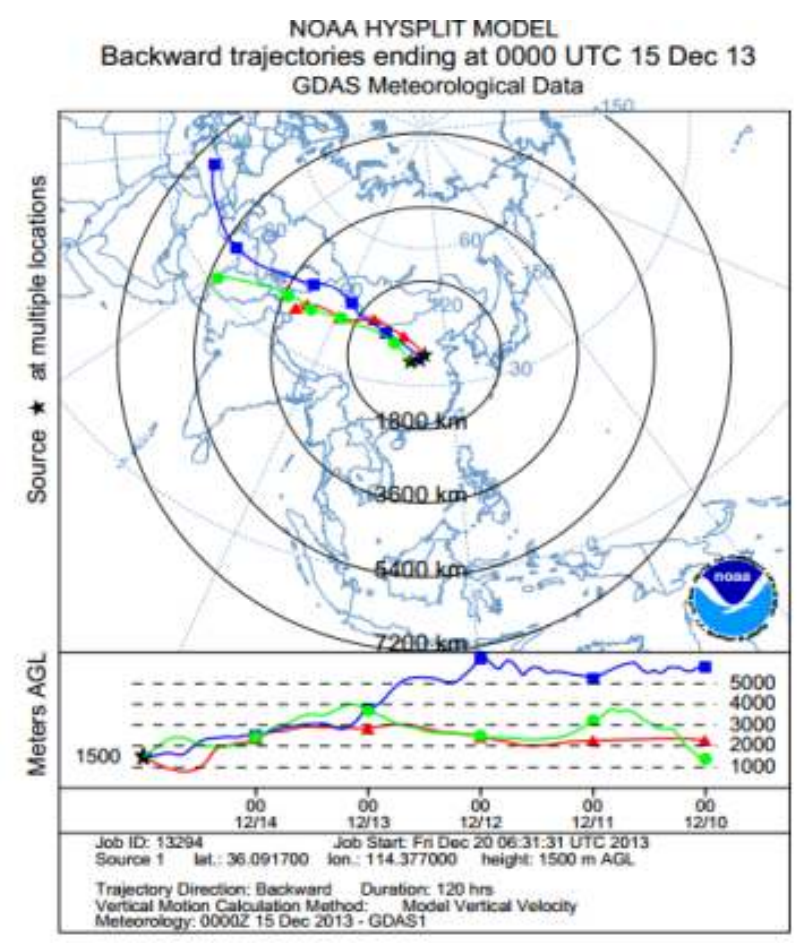

Figure 19. Backward trajectories from Hysplit

increased and stabilized. The overall aerosol extinction coefficient at AY was higher than that at JZ, and the peal values are $0.87 \mathrm{~km}^{-1}$ and $0.51 \mathrm{~km}^{-1}$, respectively. The pollution layer was below $1.9 \mathrm{~km}$, corresponding to the pollutant transmission layer in a low level jet (LLJ) [30] of stable or neutral boundary layer. For two days, it was observed that the height of the mixing layer grew linearly over time. When the height of the mixing layer grows to the height of the pollutant transmission belt in the nocturnal boundary layer, the vertical mixing effect would result in rapid concentration of pollutants on the ground. Therefore, there was increase in aerosol values, as well as in local pollutants discharge during the days; the downward transmission from the higher layers was also an important factor. Compared with AY and JZ, the air at SMX was cleaner and the height of pollutants was lower at $1.2 \mathrm{~km}$ below, but by the evening of June13 the pollution became serious.

\section{Satellite}

From the satellite results in Fig 20, it can be observed that high $\mathrm{NO}_{2} \mathrm{VCD}$ values existed during the haze period. From the daily variations in $\mathrm{NO}_{2} \mathrm{VCD}$ values between Nov and Dec at AY, JZ and SMX (seen in Fig 21), it can be seen that the results at AY clearly indicate a relation between $\mathrm{NO}_{2}$ VCD values and haze. For example, at AY, the daily average value of $\mathrm{NO}_{2} \mathrm{VCD}$ 

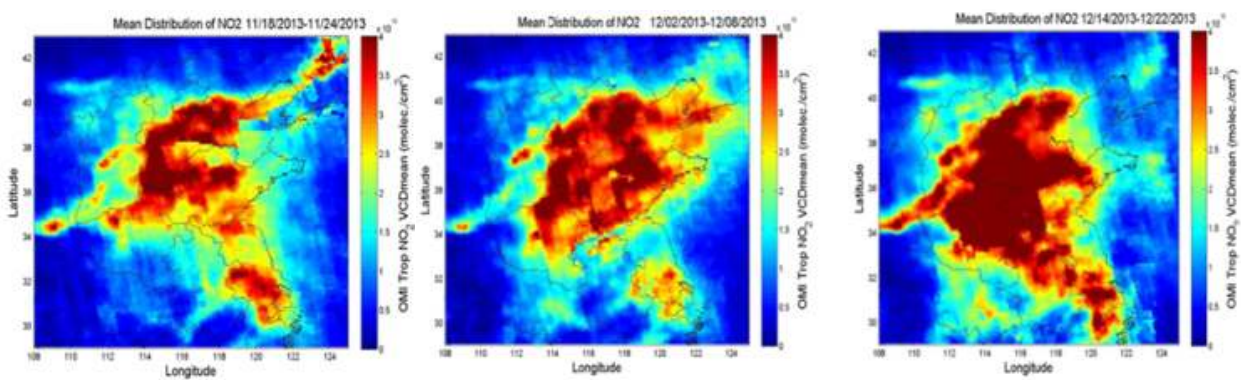

Figure 20. $\mathrm{NO}_{2} \mathrm{VCD}$ distribution result chart from Nov 11 to Dec 20 in CCR during haze period

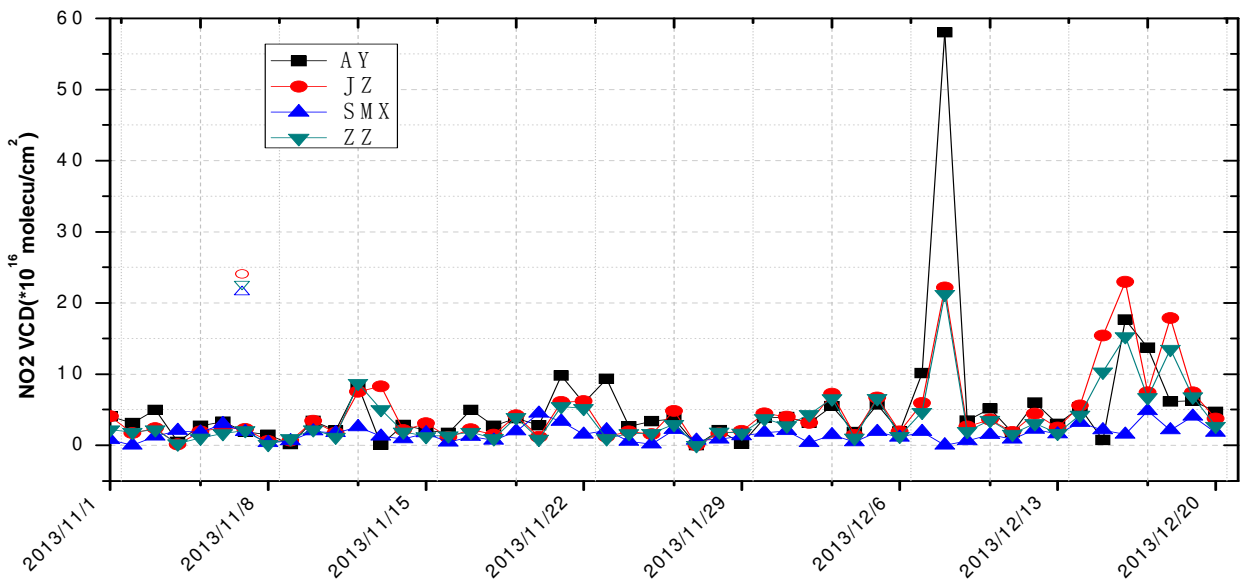

Figure 21. $\mathrm{NO}_{2}$ VCD change chart detected by OMI satellite from Nov 1 to Dec 20

during Nov 1-20 was $3.32 \times 10^{16}$ molec. $/ \mathrm{cm}^{2}$. For the first haze period during Nov 21-23, the daily average value was $8.37 \times 10^{16}$ molecule $/ \mathrm{cm}^{2}$, which was 2.5 times more than the normal average value. For the second haze period on Dec 8 , it was $5.8 \times 10^{17}$ molecule $/ \mathrm{cm}^{2}$, which was the highest and 18 times more than the normal average value. For the third haze period during Dec 16-17, it was $1.57 \times 10^{17}$ molecule $/ \mathrm{cm}^{2}$, which was 4.7 times more than the average value. From the values of $\mathrm{NO}_{2}$ during these three haze periods, which were multiple times more than the average value, it clearly follows that there exists certain relation between $\mathrm{NO}_{2}$ and haze, and that high $\mathrm{NO}_{2} \mathrm{VCD}$ values contribute to hazy weather.

\subsection{Typical straw burning process analysis (June 12-16, 2014)}

\section{Aerosols}

Wheat harvesting from June 12 to June 16 in early summer of 2014, straw burning contributed to local pollution at all the three observation points in AY, JZ and SMX (Figs 22 \& 23). At all 
these points, pollution was at its peak during June 14-15. And the biomass burning, such as straw burning, which releases particulate matter of small grain size, is confirmed by the depolarization ratio values from lidar observations.

June 13, 2014-June 14, 2014 (initial phase)

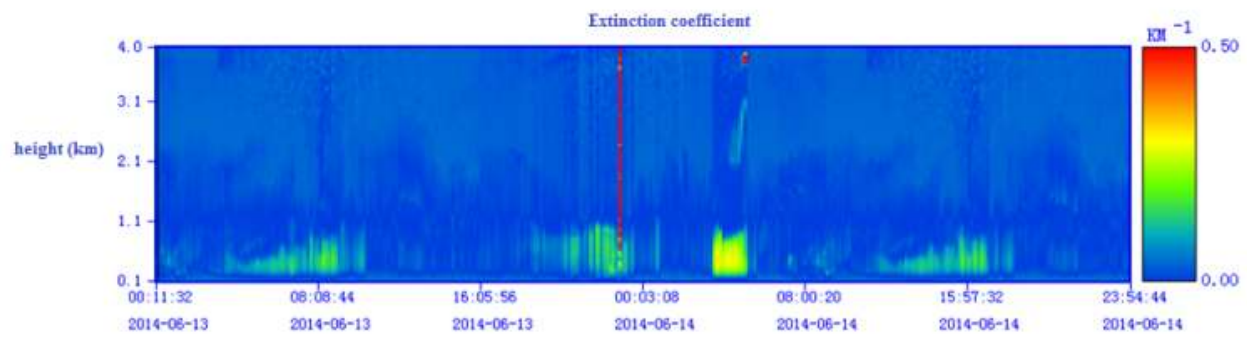

Figure 22. Spatial distribution of aerosol from June 13 to June 14,2014 at AY, CCR

June 15, 2014-June 16, 2014 (serious pollution phase)

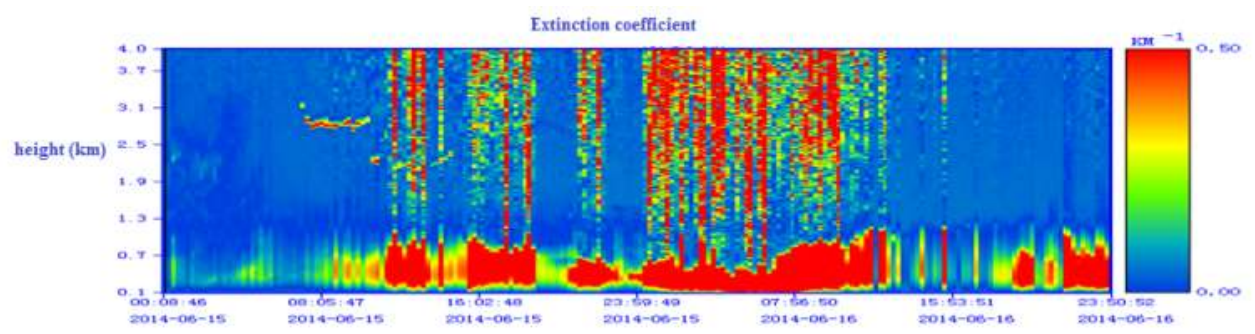

Figure 23. Spatial distribution of aerosol from June 15 to June16, 2014 at AY, CCR

During the straw burning period in CCR, the aerosol extinction coefficient fluctuated from 0.69 to $1.23 \mathrm{~km}^{-1}$. The low depolarization peak value of 0.2 confirms the presence of fine particulates. Besides particulates, usually straw burning also releases various gaseous components such as $\mathrm{CO}_{2}, \mathrm{CO}, \mathrm{NOx}, \mathrm{VOC}$, sulfuric acid gas, hydrochloric acid gas, and alkaline gas ammonia. The retention time of ammonia in the air is short, because it quickly reacts with acidic gases or acidic particulate matter, and the resulting components can be precipitated on the particle surfaces of the particulate matter leading to the generation of new condensation nucleus. The aging process will increase the amount of particulate matter, which can lead to the increase in particulate emission factors. The burning of straw near CCR, together with surrounding pollution transmission, aging of particulate matter during long distance transmission, and the emission factors such as diameter aggravated local pollution. 


\section{Pollution gas}
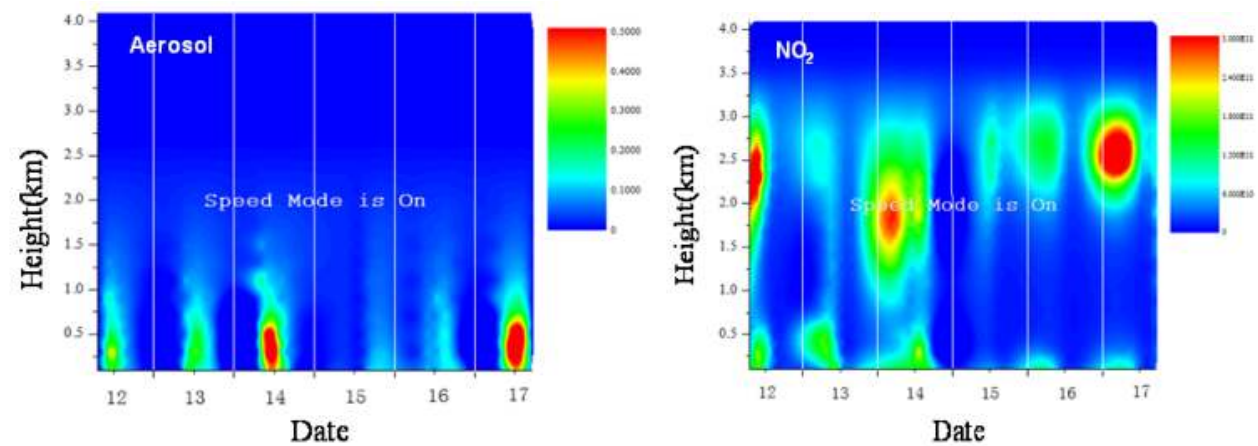

Figure 24. Aerosol and $\mathrm{NO}_{2}$ profiles from June 15 to June16, 2014 at AY, CCR

$\mathrm{NO}_{2}$ and $\mathrm{SO}_{2}$ values were at low level for most of the time, but at some stages during the measurement period from the end of May to the middle of June, they were at high level. According to the results of aerosol and $\mathrm{NO}_{2}$ for the period June 12 to 17 (see Fig 24), high aerosol extinction appeared at $300 \mathrm{~m}$ on June 12; it reached the peak on June 14 and diffused on June 15. It appeared on June 16 again and reached the highest level on June $17 . \mathrm{NO}_{2}$ transmission process appeared at the height of 1.8 to $2.7 \mathrm{~km}$ on June 12; it weakened on June 13 although the transmission close to the ground was stronger. The transmission process appeared again at the height of 1.5 to $2.2 \mathrm{~km}$ on June 14, which reappeared, though as a weaker one, on June 15 and 16 at the height of 2.2 to $3 \mathrm{~km}$. But the transmission remaining at the same height became stronger on June 17.

\section{Fire spots and backward trajectory}

To identify the sources of pollution transmission, local information was taken as the reference. But during the wheat harvesting season, the burning of straw on the surrounding farmlands was believed to be the main cause for high values of pollution. Therefore, the analysis was made by referring to the satellite fire spots diagram of Ministry of Environmental Protection, which is shown in Fig 25.

From these fire spots [31], it was inferred that multiple fire points existed around AY and JZ since June. However, by the middle of June they increased and many more fresh points appeared in the agricultural area of south CCR in the southeast. The backward trajectories, shown in Fig 26, indicate that concentrated burning of wheat straw brought about peripheral transmission.

From the foregoing results of aerosols and pollution gas, it emerges that the transportation brought by wheat straw burning manifested mainly as rapid increase of PM10, which is related to moisture absorption and expansion of particulate matter during transportation process. $\mathrm{NO}_{2}$ and $\mathrm{SO}_{2}$ were at their peaks on June 13 and 14 respectively; so, the amplification was not 


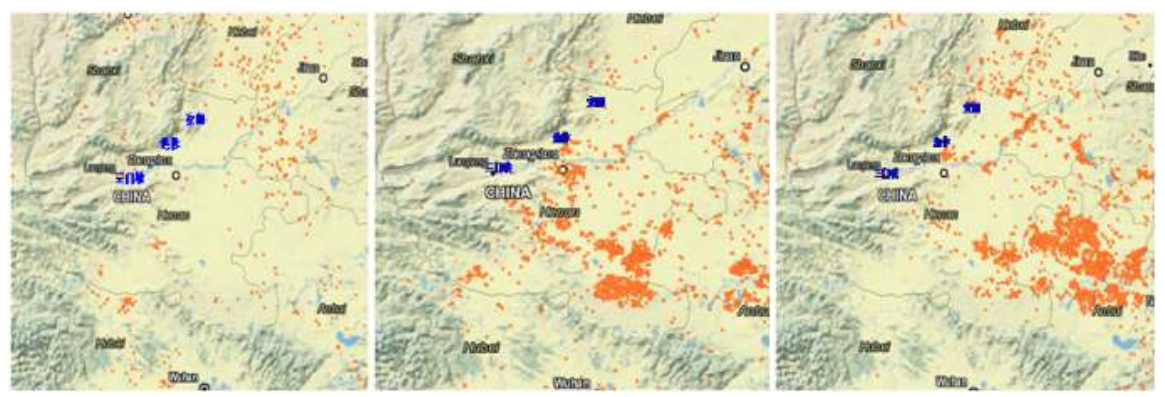

Figure 25. Fire spots from May 26 to June 1, June 2 to June 8, and June 9 to June 15

NOAA HYSPLIT MODEL

Backward trajectories ending at 0200 UTC 14 Jun 14

GDAS Meteorological Data

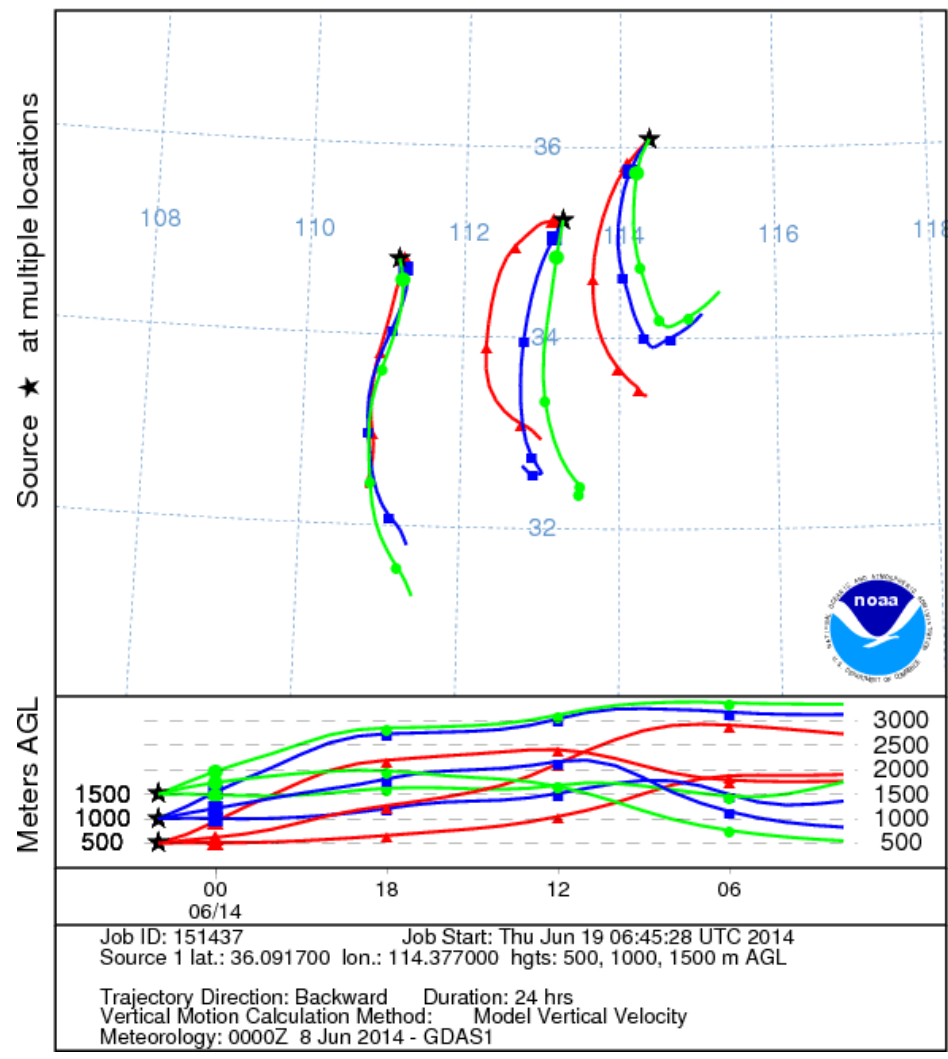

Figure 26. Backward trajectories from Hysplit 
as obvious as that of PM10. For evaluating the influence of wheat straw burning on local air pollution, the values of $\mathrm{NO}_{2}$ and $\mathrm{SO}_{2}$ on June 11, before wheat straw burning, were taken as the background values. The $\mathrm{NO}_{2}$ values obtained after wheat straw burning on June 13, and again the $\mathrm{SO}_{2}$ values obtained on June 14, were recorded and evaluated. From these evaluation results, it's concluded that from the end of May to the middle of June, concentration of gaseous pollutants $\left(\mathrm{NO}_{2}\right.$ and $\left.\mathrm{SO}_{2}\right)$ and particulate matter increased obviously due to straw burning in $\mathrm{CCR}$ and surrounding cities.

\section{Conclusions}

CCR is an important industrial site in the mid- west region of China. Historical review of satellite data shows that the cities with relatively serious air pollution are confined mainly to the north because of their geographic location, weather conditions and industrial activity. Besides, the "accumulation zone" of pollutants exists in the region east of Tai-hang Mountains. Analysis of the data obtained from stereoscopic monitoring of the selected sites shows that the prevalence of pollution at the three sites, AY, JZ and SMX, was almost simultaneous. However, AY was characterized by local pollution (local source) and JZ by near-ground pollution, where the pollution concentration was also higher due to higher emission of industrial gases. Though local pollution was milder at SMX, it still can be easily aggravated by northwest sand dust transportation. Through statistical analysis of satellite and ground monitoring data, pollution was more serious during the 1st and 4th quarters (winter and spring), followed by the 2nd quarter and the 3rd quarter. During the heating period, the air pollution intensified obviously, because the urban energy consumption structure was still coal-oriented. During late May to mid-June, straw burning in the south CCR and surrounding provinces, such as Anhui and Jiangsu, contributed to the increase of aerosol, $\mathrm{NO}_{2}$ and $\mathrm{SO}_{2}$, in some cities of CCR.

As for the reasons for the complex process of haze formation, it was found that local pollution (local sources) was the main cause, besides the effect of superposition of pollution transportation in some time frames. Near-ground pollution at the three sites was caused mainly by local pollution (industrial emission, motor vehicle exhaust, coal combustion, etc.) and pollution transportation of some northern cities in the southeast direction. AY was more affected by local transportation and emissions from some industrial parks, and JZ by near-ground local pollution. Moreover, pollution concentration was higher at JZ than that at AY because of more industrial emissions. Local pollution at SMX was comparatively less obvious, but was lasting longer due to the unfavorable diffusion condition. In CCR, formation of ground weather situations of uniform-pressure field and North China low pressure, which are bad for pollutant diffusion, is easy. Such weather has lower ground pressure field, and smaller speeds of ground and low-altitude winds, which are sometimes calm. It is often accompanied with stronger radiation inversion or low-altitude temperature inversion that is difficult to eliminate. The structure of lower atmosphere layer is stable and might contribute to higher pollution.

So far many efforts were made from ground based and space borne observations to study aerosol distribution and properties, along with model simulations, but such integrated studies 
are still limited over the East Asian, especially in CCR region in China. Satellite observations provide time constrained observations of aerosol vertical distributions but ground based lidar can give information on the evolution of the distribution over a location. Thus the optical properties of aerosols or gaseous pollutants obtained from ground-based remote sensing technology, especially lidar and DOAS is being studied to determine the aerosol optical characteristics and source origin. In the future, the more integrated combination of lidar, satellite data, in-situ instruments, and sunphotometer data will help us to improve the characterization of a variety of aerosol events and get deeper insight into the mechanism of long-range transportation of pollution in China. Furthermore, the information of vertical distribution of haze layer during long-range transportation could permit us to make better assessment of the effect of aerosols on the radiative forcing and climate change.

\section{Acknowledgements}

This work was supported by the Funding from Henan Program (Researches on Atmospheric Haze pollution in Henan Province), Major State Basic Research Development Program of China (2014CB447900) and NSFC (41305126). The authors are also thankful to the NOAA Air Resources Laboratory (ARL) for providing the HYSPLIT transport and dispersion model used in this research.

\section{Author details}

Wenqing Liu, Zhenyi Chen*, Pinhua Xie, Jianguo Liu and Tianshu Zhang

*Address all correspondence to: zychen@aiofm.ac.cn

State Environmental Protection Key Laboratory of Optical Monitoring Technology, Ministry of Environmental Protection of the People's Republic of China, Anhui Institute of Optics \& Fine Mechanics, Chinese Academy of Sciences, Hefei, Anhui, P.R. China

\section{References}

[1] Ramanathan, V., P. J. Crutzen, J. T. Kiehl, and D. Rosenfeld, Atmosphere: aerosols, climate, and the hydrological cycle. Science.,2001, 294, 2119-2124.

[2] Ian G. C., Guand C. L. and Jami H., China's Growing Urban Health Inequalities: The Challenges Ahead, J. Management and Sustainability, 2013, 3(2):10-18 
[3] Sun Y. L., Zhuang G. S., Wang Y., Han L. H., Huo G. J. and Dan M., The air-borne particulate pollution in Beijingconcentration, composition, distribution and sources. Atmos. Environ., 2004,38(35): 5991-6004

[4] Tie, X., Brasseur G., Zhao C. S., Granier C., Massie S., Qin, Y., Wang P. C., Wang G. L., Yang P. C. and Richterg A., Chemical characterization of air pollution in Eastern China and the Eastern United States. Atmos. Environ., 2006,40, 2607-2625

[5] Wu, D., Deng X. J., Bi X. Y., Li F., Tan H. B., Liao G. L., Study on the visibility reduction caused by atmospheric haze in Guangzhou area. J. Tropical Meteorology, 2006,13, $77-80$

[6] Zhang, Y. H., Hu M., Zhong L. J., Wiedensoher A., Liu S. C., Andreae M. O. and Fan F. J., Regional integrated experiments on air quality over Pearl River Delta 2004 (PRIDE-PRD2004), Atmos. Environ.,2004,42,6157-6173

[7] Wang Y.S., Xin J. Y., Li Z. Q., Wang P. C., Wang S. G., Wen T. X., Sun Y., AOD and Ångström Parameters of Aerosols Observed by the Chinese Sun Hazemeter Network from August to December 2004, Environ. Sci., 2006,27(9)

[8] Tesche, M., Ansmann A., Müller D., Althausen D. and Engelman R., Particle backscatter, extinction, and lidar ratio profiling with Raman lidar in south and north China, Appl. Opt., 2007,46(25):6302-8

[9] Xiao, R., Takegawa N., Zheng M., Kondo Y., Miyazaki Y., Miyakawa T., et al.,Characterization and source apportionment of submicron aerosol with aerosol mass spectrometer during the PRIDE-PRD 2006 campaign, Atmos. Chem. Phys., 2001,11, 6911-6929

[10] Li, Z., et al., Preface to special section on East Asian Studies of Tropospheric Aerosols: An International Regional Experiment (EASTAIRE), J. Geophys. Res., 2007,112, D22S00, doi:10.1029/2007JD008853.

[11] Li, Z., et al., East Asian Studies of Tropospheric Aerosols and their Impact on Regional Climate (EAST-AIRC): An overview, J. Geophys. Res., 2011,116, D00K34, doi: 10.1029/2010JD015257

[12] Atsushi, S., Nobuo S., Ichiro K. A., Itsushi U., Toshiyuki M., Naoki K.,et al., Continuous observations of Asian dust and other aerosols by polarization lidars in China and Japan during ACE-Asia, J. Geophys. Res.,2004 109, D19S17

[13] He, Q. S., Li C. C., Mao J. T. and Li P. R., A study on the aerosol extinction-to-backscatter ratio with combination of micro-pulse LIDAR and MODIS over Hong Kong, Atmos. Chem. Phys., 2006, 3243-3256

[14] Müller, D., Tesche M., Eichler H., Engelmann R., Althausen D., Ansmann A., et al,Strong particle light absorption over the Pearl River Delta (south China) and Beijing (north China) determined from combined Raman lidar and Sunphotometer observations, Geophys. Res. Lett., 2006, 29 (17) 
[15] Mattias J., Bo G., Tong Y., Lin T., Chen D.L., Li H.J., et al., Quantification of total emission of air pollutants from Beijing using mobile mini-DOAS, 2008,Atmos. Environ.,42(29), 6926-6933

[16] Meng X.L., Fan X.Y., Meng X., Zheng J.P., Mason R.,Submicron-sized fluid inclusions and distribution of hydrous components in jadeite, quartz and symplectite-forming minerals from UHP jadeite-quartzite in the Dabie Mountains, China: TEM and FTIR investigation, 2009,Applied Geochemistry,24(4), 517-526

[17] Cheng, Y., Lee S. C., Ho K. F., Wang Y. Q., Cao J. J., Chow J. C. and Watson J. G., Black carbon measurement in a coastal area of south China, J. Geophys. Res. Atmos., 2006, 111, D12310, doi: 10.1029/2005JD006663

[18] Franke, K., A. Ansmann, D. Muller, D. Althausen, C. Venkataraman, M. S. Reddy, F. Wagner and R. Scheele (2003), Optical properties of the Indo-Asian haze layer over the tropical Indian Ocean, J. Geophys. Res., 108, D2, 4059, doi: 10.109/2002JD002473

[19] Klett, J. D., Stable analytical solution for processing lidar returns, Appl. Opt., 1981, 20, 211-220,

[20] Frederick G. Fernald. Analysis of atmospheric lidar observations: some comments, Appl. Opt., 1984, 23(5), 211-220

[21] Xu J., Xie P.H., Si F.Q.,Li A.,et al., Comparison of NO2 slant columns between two ground-based Max-DOAS, Spectroscopy and Spectral Analysis, 2012,32(2),558-564

[22] Wang Y., Li A., Xie P.H., Chen H., Xu J.,Wu F. C., Liu J.G., Liu W.Q., Retrieving vertical profile of aerosol extinction by multi-axis differential optical absorption spectroscopy, Acta Phys. Sin.,2013, 62(18), 180705

[23] Wu J.G. Modern Fourier Transform Infrared Spectroscopy and Its Application, Beijing: Scientifical and Technical Documents Press,1994,1, 492-505

[24] Manne K, Ph. D. Dissertation, Sweden: Chalmers University of Technology.2005

[25] Fransson, K and Mellqvist, J., Measurements of VOCs at Refineries Using the Solar Occultation Flux Technique, Report to Preem Environmental foundation, Göteborg, 2002

[26] Wang T., Wang P.C., Yu H., Zhang X.Y., Zhou B.,Si F.Q., et al., Intercomparison of slant column measurements of NO2 by ground-based MAX-DOAS, Acta Phys. Sin. 2013, 62(5), 054206

[27] Wu F.C., Xie P.H., Li A.,Xu J., Shi P., Qin M.,Wang M.H., et al., Studies on the Remote Measurement of the Distribution ion of City Gaseous Pollutant by Mobile Passive Differential Optical Absorption Spectroscopy, Spectroscopy and Spectral Analysis, 2011,31(3),583-588 
[28] Witte J.C., Duncan B.N., Douglassb A.R., Kurosuc T.P., Chancec K., Retscherd C.,The unique OMI HCHO/NO2 feature during the 2008 Beijing Olympics: Implications for ozone production sensitivity, Atmos. Environ.,2011, 45(18), 3103-3111

[29] Draxler, R. R., and Rolph G. D., HYSPLIT (Hybrid Single-Particle Lagrangian Integrated Trajectory) Model access via NOAA ARL READY, (2003) web site (http:// www.arl.noaa.gov/ready/hysplit4.html), NOAA Air Resources Laboratory, Silver Spring, MD.

[30] Hu X.M., Klein P.M., Xue M., Zhang F.Q., Doughty D.C., Forkel R., Joseph E, Fuentes J.D., Impact of the vertical mixing induced by low-level jets on boundary layer ozone concentration, Atmos. Environ., 2013,70,

[31] http://hjj.mep.gov.cn/stjc/ 